\title{
Измерение стоимости корпорации в условиях риска и неопределенности инвестиционной деятельности
}

\author{
Осипов Я.И. ${ }^{4}$
}

В данной статье рассмотрены методологические проблемы измерения свободных денежных потоков, как фундамента стоимости корпоращии в условиях риска и неопределенности инвестиционной конъюнктуры финансового рынка. Выделены ключевые факторы и определена модель стоимости корпоращии на основе принципа стационарности прогнозируемого потока свободных денежных средств. Предложена методика определения будущей стоимости в условиях неопределенности возврата денежных средств, вложенных в результате инвестиционной деятельности корпорации.

$$
\text { JEL: G39 }
$$

Ключевые слова: стоимость корпорачии, свободные денежные потоки, инвестиционная деятельность

\section{Введение}

Инвестирование при неопределенности конъюнктуры рынка - серьезная и рискованная операция. Инвестор ожидает от корпорации возврата вложенных в дело средств с прибылью. Поток свободных денежных средств (возврат инвестиций) от результатов хозяйственной деятельности корпорации и определяет ее стоимость. Менеджеры всегда уверяют инвесторов, что они управляют стоимостью, стремятся ее увеличить для инвесторов. Но в условиях неопределенности конъюнктуры рынка убедить в этом инвесторов бывает довольно таки трудно. Поскольку в основе стоимости лежат будущие денежные потоки. Проблема состоит в том, что менеджеры не могут точно спрогнозировать денежные средства, свободные от выполнения стратегических проектов корпорации. Во многом это объясняется тем, что менеджеры плохо понимают категорию «стоимость корпорации» и ключевые факторы ее увеличения. Деятельность корпорации в лучшем случае оценивается ими показателем чистой прибыли, что не является значимым для инвестора. Инвестор ожидает от деятельности корпорации свободных, справедливых денежных потоков, которые можно извлечь из корпоративной хозяйственной деятельности без ущерба. Дело усугубляется и тем обстоятельством, что сам инвестор в условиях неопределенности иррационально ведет себя на финансовых рынках: что во многих случаях - как азартный игрок в стремлении достичь финансового успеха. Невозврат денежных средств возможен вследствие эффекта «безвозвратных» издержек (sunk cost), который часто встречается в финансовой практике инвесторов при исполнении корпорацией стратегических проектов.

\section{1. Методологические проблемы в определении и управлении стоимостью в условиях неопределенности и риска инвестиционной деятельности корпорации}

Чтобы преуспеть, корпорация стремится максимально полно использовать предоставленные ей инвесторами (акционерами, кредиторами) инвестиции. Любая корпоративная инвестиция исходит из одного из главных экономических принципов возвратности (отдачи) вложенных средств. Поэтому цель инвестора - возврат с

\footnotetext{
${ }^{4}$ Магистр экономики. Специализация: Стратегическое управление финансами фирмы. Государственный Университет - Высшая Школа Экономики. Начальник экономического отдела ЗАО «ГлобалЭнергоТрейд». Аспирант Московского государственного университета экономики, статистики и информатики.
} 
приумножением для себя вложенных в дело денежных средств, которые рассматриваются как поток свободных денежных средств. Свободные денежные средства - это такие денежные средства, которые можно свободно изъять из финансового оборота без ущерба для хозяйственной деятельности корпорации. Это поток либо дивидендов акционеров, либо процентов за предоставленный кредит кредиторами. Менеджмент же корпорации различного уровня (хозяйственного, финансового и т.д.) должен стремиться так поставить дело, чтобы свободный денежный поток был постоянно бурным, источники его не высыхали и возрастающе фонтанировали. Именно возвращаемый свободный денежный поток лежит в основе формирования стоимости корпорации.

Допустим, что в некоторой корпорации, существующей $\mathrm{n}$ лет, в i-м году образуются свободные денежные средства $\mathrm{CR}_{\mathrm{i}}$ (Cash Revenue), т.е. такие, которые безболезненно могут быть изъяты инвесторами из хозяйственного оборота корпорации. Инвестор, всегда делая ставку на будущий результат, с целью увеличения возвратов может в конце і-го периода произвести новые инвестиции $\mathrm{I}_{\mathrm{i}}$ (investment). Источником новых инвестиций могут быть (полностью или частично) либо свободные средства $\mathrm{CR}_{\mathrm{i}}$ корпорации, либо привлеченные средства из источников вне корпорации, например новые кредиты. Тогда итоговая величина чистых или просто свободных денежных средств корпорации в і-м году $\mathrm{CF}_{\mathrm{i}}$ (Cash Flow) за вычетом инвестиций определяется как: $C F_{i}=C R_{i}-I_{i}$. Свободный денежный поток, произведенный за n лет деятельности корпорации, составит величину:

$$
N V=\sum_{i=0}^{n} C R_{i}-I_{i}=\sum_{i=0}^{n} C F_{i}
$$

где NV (Net Value) - чистая стоимость или просто стоимость хозяйственной деятельности корпорации за $\mathrm{n}$ лет, которая определяется разницей между результатом и вложенными в корпорацию денежными средствами.

Поскольку денежные средства, вложенные инвесторами в корпорацию, имеют разную временную ценность, стоимость корпорации EV (Enterprise Value) окончательно можно определить как:

$$
E V=\sum_{i=0}^{n} \frac{C F_{i}}{(1+r)^{i}}+\frac{T V}{(1+r)^{T}},
$$

где $\mathrm{n}$ - количество лет периода, в котором реализуются базовые проекты хозяйственной деятельности корпорации, приносящие непрерывный поток свободных денежных средств; Т - год оценки аккумулированных инвестиций $\mathrm{T}=\mathrm{n}$; TV (Terminal Value) - стоимость компании на период $\mathrm{T}=\mathrm{n} ; \mathrm{r}$ - средневзвешенная цена капитала, WACC (Weight Average Cost of Capital).

Однако практическое применение теории стоимости корпорации, лежащей на принципе возвратности потока свободных денежных средств, сталкивается с трудностями и принципиальными проблемами. Дело в том, что цели у инвесторов и менеджмента в управлении стоимостью корпорации могут быть различны или пути достижения этих целей могут быть различны, несмотря на то что вроде бы источником доходов у тех и других является корпоративная прибыль [Modigliani, Miller, 1958; Modigliani, Miller, 1961; Modigliani, Miller, 1963; Ohlson, 2001]. Инвестор понимает под стоимостью корпорации ее справедливую рыночную цену [Брейли, Майерс, 2005; Бригхэм, 2007; Коупленд, 2005;], очищенную от спекулятивных и ажиотажных колебаний и обеспечивающую доходность (отдачу) вложенных средств не ниже WACC. Инвестирование - это всегда ставка на будущий, ожидаемый результат. Разочарование инвестора наступает, когда нет возврата (отдачи) от постоянных и всевозрастающих вливаний в корпорацию. Причина безвозвратности вложений для многих инвесторов неясна. Эта неясность приводит к оттоку капитала из корпорации. Менеджер же вполне может быть доволен и общей массой получаемой корпоративной прибыли. Его в последнюю очередь интересует отдача, эффективность вложенных средств, а также образование свободных денежных средств 
акционеров.

Эти трудности могут возникать по следующим причинам.

Во-первых, вследствие существования мифа о рациональном поведении инвесторов на финансовых рынках. Практика инвестирования показывает, что во многих случаях инвестор ведет себя иррациональным образом, что вызывает скепсис об эффективности рынка. В классических микро- и макроэкономических финансовых теориях и моделях лежит предположение о рациональном поведении инвестора и менеджера на рынке капитала и инвестиций. Аксиома рационального поведения финансового менеджера и инвестора исходит из концепции «рационального» прагматизма, согласно которой индивидуум стремится всегда к большей выгоде, решения принимает на основе анализа и снижения предельных затрат, а также максимизации функции полезности, пытается избежать риска и в условиях неопределенности следует выводам теории вероятности, математической статистики и эконометрики. Но является ли инвестиционное поведение действительно рациональным? По мнению М. Блауга [Блауг, 2004], многие экономические теории не находят практического подтверждения. В экономике, так же как и в финансовом менеджменте, не представляется возможным экспериментальным путем подтвердить истинность рациональным образом выдвигаемых теорий, взглядов и моделей. Выход из такого положения - использовать игровой элемент, подход как средство доказательства истинности выдвигаемой экономической доктрины, применять выводы и рекомендации поведенческих финансов, изучать иррациональность поведения участников рынка. Правда, Пол Самуэльсен отмечает, что многие инвесторы не понимают, как извлечь выгоду из поведенческих аномалий, даже если они принимают гипотезу неэффективности рынка [Бернштейн, 2009].

Во-вторых, менеджеры всегда пытаются убедить инвесторов в том, что управление корпорацией выполняется на основе стоимости с помощью таких методов, как NPV, MPV, CFROI, EE или EVA [Рош, 2008]. Однако до сих пор в оперативном управлении корпорацией предпочтение отдается показателям отчета о прибылях и убытках. Прежде всего - особо популярному ныне показателю прибыли до вычета процентов, налога, износа и амортизации EBITDA (Earnings Before Interests, Tax, Depreciation and Amortization), чистой прибыли NI (Net Income) или мультипликаторам финансового рынка, в частности, такому показателю, как P/E, где P - рыночная цена одной акции, а Е - чистая прибыль корпорации на одну акцию. Причем влияние всех этих показателей на стоимость оценивается менеджерами субъективно, на основе их собственного, индивидуального опыта. Но опыт, не подкрепленный математическим расчетом, может в стратегическом плане привести к непоправимым ошибкам в инвестиционной политике корпорации.

В-третьих, менеджеры корпорации не до конца понимают глубины концепции стоимости и ключевых факторов бизнеса, оказывающих на нее определяющее влияние и воздействие. Инвесторы еще дальше стоят от понимания этих проблем.

Для понимания сути проблемы рассмотрим простую модель бизнеса. Пусть во вновь организуемую корпорацию внесена инвестиция I, истраченная на приобретение оборудования со сроком амортизации Т. Производственные активы РАС учтены по первоначальной стоимости и равны I. Рабочий оборотный капитал корпорации WC равен нулю $(\Delta W C=0)$. По истечении срока амортизации оборудования корпорация прекращает свое существование. Тогда при условии постоянства цен на выпускаемую продукцию и расходов на ее производство и реализацию в корпорации будет инициирован ежегодный постоянный свободный денежный поток в размере:

(3) $\mathrm{CR}=\mathrm{NOPLAT}+\mathrm{D}$,

где NOPLAT (Normalized Operating Profit Less Adjusted Taxes) - нормализованная операционная прибыль, скорректированная на налог NOPLAT = EBIT (1 - Tax); часто вместо EBIT применяется EBITDA, a D - амортизация (износ).

В этом случае стоимость корпорации определяется отношением: 
(4)

$$
E V=\sum_{i=0}^{T} \frac{C F_{i}}{(1+r)^{i}}=\sum_{i=1}^{T} \frac{N O P L A T+D}{(1+r)^{i}}-I
$$

Поскольку для данной модели бизнеса свободный денежный поток является аннуитетом (постоянная срочная рента), значение стоимости компании EV можно выразить таким образом:

$$
\mathrm{EV}=(\mathrm{NOPLAT}+\mathrm{D}) \mathrm{w}(\mathrm{r})
$$

где

$$
w(r)=\frac{1}{r}\left(1-\frac{1}{(1+r)^{T}}\right)
$$

коэффициент аннуитета, являющийся гиперболической (убывающей) функцией от $\mathrm{r}=$ WACC . Вынося за скобки инвестиции I, окончательно получим факторную модель стоимости корпорации $\mathrm{EV}$ :

$$
E V=I\left(\frac{N O P L A T+D}{I} w(r)-1\right) .
$$

Введем коэффициент рентабильности активов ROAA (Return On Accumulated Asserts) или просто ROA (Return On Asserts), определяя его как:

$$
R O A=\frac{C R}{I}=\frac{N O P L A T+D}{I} .
$$

Показатель ROA выражает собой рентабельность одной денежной единицы инвестиции I или активов РАС в виде свободного потока денежных средств, которые возвращаются в каждом году инвестору.

Тогда

$$
E V=I \cdot(R O A \cdot w(r)-1) .
$$

Из последнего выражения можно сделать вывод, что стоимость корпорации определяется тремя факторами:

- Объемом инвестиций I или аккумулированных инвестиций в виде активов РАС.

- Возвратом (отдачей) инвестиций или аккумулированных активов РАС.

- Средневзвешенными затратами на капитал WACC, которые задают напор возвращаемых средств, выраженный коэффициентом аннуитета w(r).

Таким образом, для эффективного управления стоимостью корпорации менеджменту необходимо постоянно увеличивать объемы инвестиций I, а также в результате увеличения коэффициента рентабельности активов ROA снижать средневзвешенные затраты на капитал корпорации.

Доходность вложенных в корпорацию инвестиций I для данной модели бизнеса (внутренняя ставка доходности капитала корпорации IRR) определяется путем решения уравнения:

$$
R O A \cdot w(r)-1=0 .
$$

На практике управление стоимостью ограничивается расчетом менеджментом внутренней ставки доходности капитала корпорации IRR и выяснением степени достижимости цели корпорации: возврат инвестиций с заданной рынком доходностью капитала WACC. Но чтобы обеспечить рост стоимости, нужно обратить внимание на фактор еe роста - ROA.

В данной простой модели бизнеса представлена всего одна инвестиция I. В реальной же практике трудности в управлении стоимостью корпорации у менеджмента возникают, когда корпорация осуществляет множество инвестиций $\mathrm{I}_{\mathrm{i}} \mathrm{c}$ различным сроком амортизации (износа), а также когда нет аннуитета от различных инвестиций $\mathrm{I}_{\mathrm{i}}$.

B-четвертых, инвестирование связано с большим риском невозвратности (sunk cost) или неполной возвратности денежных средств, обусловленным неопределенностью конъюнктуры рынка. Инвестирование - это чрезвычайно серьезное и рискованное дело. На 
практике инвестор пытается страховать риски неопределенности рынка за счет применения широкой диверсификации инвестиционного портфеля и использования опционов. Зная выводы исследований поведенческих финансов, он пытается не попасть в ловушку иррационального поведения на финансовом рынке. Например, такую, как часто встречающийся в корпоративных финансах (что подтверждено историческим опытом) инвестиционный эффект «вливания», приводящий к безвозвратной трате без полной отдачи все увеличивающихся инвестиций.

Но несмотря на страхование риска, инвестору заранее неизвестно, что модель бизнеса, предложенная корпорацией, будет приносить доход в будущем. В этом плане теория стоимости сталкивается с принципиальной методологической проблемой. В соответствии с данной теорией, в основе стоимости корпорации лежат потоки свободных денежных средств $\mathrm{CF}_{\mathrm{i}}$, которые в будущем должны быть созданы в результате хозяйственной деятельности корпорации. Но будущего точно знать никто не может. Поэтому на повестке дня стоит проблема точности долгосрочного прогнозирования хозяйственной деятельности корпорации. Либо необходимо подобрать новую методологию (об источниках генерации будущих свободных денежных потоков), наиболее приближенную к практике. Однако существующие методы прогнозирования могут быть неточными. Надежность прогноза во многом зависит от субъективных оценок и предпочтений автора модели. Что нарушает концепцию справедливой цены в оценке стоимости корпорации, ожидаемую инвесторами.

\section{2. Модель оценки и управления стоимостью корпорации в условиях риска и неопределенности на финансовых рынках}

На финансовых рынках у инвестора всегда есть альтернатива экономического выбора, определяющая выгодное, рациональное направление применения инвестиционных ресурсов. Инвестор всегда пытается сравнить ожидаемый уровень дохода на капитал с текущей нормой процента по ссудам. Дж. М. Кейнс скептически относился к возможности определения дохода от инвестиционного проекта в долгосрочной перспективе [Кейнс, 1999]. Принятие инвестиционного решения он больше связывал с психологическим состоянием инвестора, определяемым как уверенность в том, что правила игры на весь инвестиционный период будут постоянны и что с ростом доходов он имеет склонность к сбережению и накоплению нежели, чем к потреблению. То есть в условиях неопределенности рынка институциональная (психологическая) составляющая во многом определяет инвестиционное поведение потенциального корпоративного инвестора. И все же с точки зрения инвестора инвестирование капитала в корпорацию зависит от неизменности нормы прибыли, получаемой корпорацией на протяжении длительного периода времени и от того, что норма прибыли не меньше или равна рыночной ставке процента по ссудам.

Из трех ключевых факторов стоимости - возврата (отдачи) ROA, инвестиций I и средневзвешенной стоимости капитала WACC - именно показатель ROA является действенным и чувствительным показателем наращивания стоимости корпорации. Он имеет естественный экономический смысл: это - показатель эффективности и отдачи использования инвестиций корпорации, рождающих поток денежных средств. Поскольку полезным эффектом от инвестиций является свободный денежный поток $\mathrm{CR}_{\mathrm{i}}$, для определения эффективности инвестиций за определенный период следует соотнести $\mathrm{CR}_{\mathrm{i}}$ со средними значениями производственных активов PAC за тот же период. Определим ROA как:

$$
R O A=\frac{C R}{\overline{P A C}}=\frac{N O P L A T+D}{\overline{P A C}},
$$

где NOPLAT - нормализованная прибыль, скорректированная на налог; D амортизация (износ); $\overline{P A C}$ - среднегодовые производственные активы по первоначальной стоимости 
В случае если в период функционирования корпорации происходит амортизация активом, их средний период амортизации Т равен:

$$
T=\frac{\overline{P A C}}{D} .
$$

Тогда с учетом периода амортизации активов ROA примет вид:

$$
R O A=R O P P A+\frac{1}{T}
$$

где

$$
R O P P A=\frac{N O P L A T}{\overline{P A C}} .
$$

Показатель ROPPA (Return On Profit Production Assets) представляет собой возврат от одной единицы производственных активов $\overline{P A C}$ инвестору операционной прибыли NOPLAT. Таким образом, ROA показывает вклад в эффективность двух факторов: операционной прибыли NOPLAT (показатель ROPPA) и амортизации $1 / T$, не связанной с операционной деятельностью корпорации.

Как известно, стоимость корпорации EV определяется как будущая бесконечная приведенная стоимость свободных денежных потоков:

$$
E V=\sum_{i=1}^{\infty} \frac{C F_{i}}{(1+r)^{i}},
$$
WACC.

где $\mathrm{CF}_{\mathrm{i}}$ - свободный денежный поток в і-м году; $\mathrm{r}$ - средневзвешенная цена капитала

Достоверность расчета стоимости корпорации зависит от точности оценки будущих свободных денежных потоков $\mathrm{CF}_{\mathrm{i}}$ и периода хозяйственной деятельности корпорации, в котором создается стоимость EV.

В последнем случае проблему оценки стоимости отметил Вильям Петти в «Трактате о налогах и сборах 1662 г.» [Петти, 1997]. Занимаясь налогами и сборами в Англии и Ирландии, он задается вопросом, сколько годичных рент нужно взять, чтобы определить стоимость участка земли. Бесконечность сумм годовых рент его не устраивает. Он предлагает оригинальное решение проблемы. Вместо бесконечности берется число лет, которое могут рассчитывать прожить одновременно на оцениваемом участке земли три человека: один - пятидесятилетний, другой - двадцативосьмилетний и третий -ребенок семи лет, т.е. отец, сын и внук. Тогда сумма последовательных годичных рент, составляющая стоимость участка земли, равна естественной одновременной продолжительности жизни этих троихх членов семьи. В Англии на тот период данная продолжительность составила 21 год. В течение этого периода (20-30 лет) посредством постоянных годичных рент будет создаваться стоимость земельного участка. Это правило предлагается применять и в других случаях оценки богатства страны и придать ему силу закона.

В корпоративных финансах период оценки для каждой корпорации может быть выбран индивидуально. Главное, чтобы при оценке стоимости была взята такая продолжительность хозяйственной жизни корпорации, в течение которой реализуются ее стратегические инвестиционные проекты, поскольку данная реализация в конечном итоге и определит текущую стоимость корпорации.

Оценивать будущие свободные денежные потоки $\mathrm{CF}_{\mathrm{i}}$ можно двумя способами.

Первый способ. Прогноз денежных потоков $\mathrm{CF}_{\mathrm{i}}$ выполнить средствами эконометрических моделями вида:

$$
C F_{i}=b_{0}+b_{1} \cdot R O A_{i}+b_{2} \cdot w(r)_{i}+\varsigma_{i}
$$

$$
C F_{i}=b_{0}+b_{1} \cdot R O P P A_{i}+b_{2} \cdot w(r)_{i}+\varsigma_{i}
$$


где $R O A_{i}, \quad R O P P A_{i} w(r)_{i}$ ключевые факторы стоимости, соответственно эффективность (возврат, отдача) инвестиций I или активов РАС, доходность капитала WACC; $b_{0}, b_{1}, b_{2}$ - мера чувствительности или вклада ключевого фактора в создание стоимости; $S_{i}$ - стохастический элемент неучтенных факторов эконометрической модели. В качестве фактора в модели отсутствует инвестиция I, что позволяет избежать проблемы мультиколлинеарности, влияющей на надежность и состоятельность статистических оценок $b_{0}, b_{1}, b_{2}$.

К достоинствам данного подхода относится то, что менеджеры при управлении стоимостью корпорации, используя эконометрические модели, оперируют надежными текущими финансовыми отчетными данными о хозяйственной деятельности корпорации:

- годовая финансовая отчетность корпорации;

- операционные финансовые данные корпорации;

- стратегические бизнес-планы об изменении факторов бизнеса и их влияния на стоимость компании.

К недостаткам можно отнести то, что надежность оценок зависит от длины динамических рядов корпоративной базы данных.

Второй способ. Будущий денежный поток можно оценить, исходя из выводов и гипотез теории перспектив Д. Канемана и А. Тверски [Kahneman, Tversky. 1979; Thaler, 1980], a также применяя кибернетический подход в управлении сложными объектами с обратной связью. Конечно, в корпоративных финансах ситуация во многом усугубляется неопределенностью будущего денежного потока. Но теория перспектив делает вывод о том, что, опираясь на текущее финансовое состояние корпорации, инвестор ожидает получить результат в виде свободного денежного потока, по крайней мере, не хуже текущего финансового положения. Зная о хорошем текущем финансовом положении корпорации, инвестор предполагает, что оно сохранится и в будущем. При этих обстоятельствах он оптимистичен в оценках бизнеса и начинает инвестировать. Нацеленность на конечный результат заставляет его действовать с опережением и самоуверенностью относительно отдачи вложенных средств. Это может привести, как мы видели, к эффекту «влипания» (безвозвратности вложенных в корпорацию средств), но инициированный им посредством инвестиций денежный поток уже не остановить. С технической точки зрения к такому же выводу пришел Н. Винер [Винер, 1983], вырабатывая эффективность управления кибернетической системой зенитного артиллерийского огня. Зенитная артиллерия также действует в условиях неопределенности, и местонахождение самолета в зоне обстрела неизвестно. Чтобы максимизировать поражение самолетов зенитным огнем, Н. Винер выдвинул гипотезу (статистический метод) о том, что самолет, несмотря на предпринимаемые им маневры, на коротком промежутке времени сохранит постоянное прямолинейное движение. На основе этой гипотезы он построил модель управления киберсистемой, которая циклически отслеживает перемещение самолета, поэтому зенитным установкам нужно стрелять с опережением в зону, где самолет сохраняет основное направление своего движения. Корпоративные финансы - такая же сложная кибернетическая система управления, действующая в условиях неопределенности. Таким образом, чтобы управлять стоимостью корпорацией в условиях неопределенности, выдвинем гипотезу, что приемлемый уровень стоимости корпорации сохранится в будущем. Приемлемый в том смысле, что к началу процесса инвестирования с целью нарастить корпоративную стоимость он устраивает инвестора.

Тогда на основе выдвинутой гипотезы можно предположить, что в будущем периоде $\mathrm{n}$ $=\mathrm{T}$ сохранится на прежнем уровне не только отдача от аккумулированных инвестиций ROPPA, но и активы PAC . Если за отчетный базовый период принять один год (при этом I $=0$ ), то корпорация периодически будет создавать сводные денежные потоки:

$$
C F=R O P P A \cdot P A C_{T} \text {. }
$$


Чтобы сохранить в будущем постоянные денежные потоки, необходимо периодически восстанавливать активы $\mathrm{PAC}_{\mathrm{T}}$. Средневзвешенный срок амортизации -активов $\mathrm{PAC}_{\mathrm{T}}$ равен:

$$
\delta=\left(1-\frac{D_{\Sigma}}{P A C_{T}}\right) T
$$

где $D_{\Sigma}$ - аккумулированная амортизация активов РАС

Таким образом, первое восстановление активов $\mathrm{PAC}_{\mathrm{T}}$ произойдет через $\delta$ лет после истечения срока амортизации.

Исходя из выдвинутых предположений, мы получим будущий аннуитет свободных денежных потоков, которые составят стоимость корпорации $\mathrm{EV}_{1}$ на конец базового отчетного периода:

$$
E V_{1}=\frac{R O P P A \cdot P A C_{T}}{r}-\frac{1}{1-q} \cdot \frac{P A C_{T}}{(1+r)^{\delta}},
$$

$T=\overline{P A C} / D$ - срок амортизации среднегодовых активов. Первый член данного соотношения определяет приведенную стоимость свободных денежных потоков CF, а второй приведенную стоимость инвестиций, обеспечивающих восстановление активов $\mathrm{PAC}_{\mathrm{T}}$ каждые $\delta$ лет.

Если теперь необходимо определить стоимость корпорации с учетом ее стоимости в отчетном периоде $\mathrm{EV}_{0}=\mathrm{CF}_{0}$, получим соотношение для выражения стоимости корпорации EV:

$$
E V=E V_{0}+E V_{1}=C F_{0}+\frac{R O P P A \cdot P A C_{T}}{r}-\frac{1}{1-q} \cdot \frac{P A C_{T}}{(1+r)^{\delta}},
$$

где $\mathrm{EV}_{0}=\mathrm{CF}_{0}=\mathrm{TM}-$ стоимость корпорации в отчетном (терминальном) периоде, определяемая свободным денежным потоком отчетного периода $\mathrm{CF}_{0}$.

Таким образом, получено простое количественное выражение стоимости корпорации, если изначально предполагается, что эффективность инвестиций ROPPA, a также объем аккумулированных инвестиций останутся неизменными.

Из приведенного выражения следует, что увеличение стоимости зависит от управления инвестиционным процессом I, направленным на постоянное обновление, техническое перевооружение и модернизацию производства товаров и услуг в корпорации.

Моделирование инвестиционного поведение показало, что приемлемого инвестиционного решения можно достичь всегда, несмотря на условности и ограничения рассматриваемой ситуации. В среднем износ по отраслям промышленности достигает почти $60 \%$. Более или менее лучше обстоит дело в газовой промышленности $-30 \%$ износа основного капитала. 
Степень износа основных фондов основного вида деятельности организаций на начало 2003 года

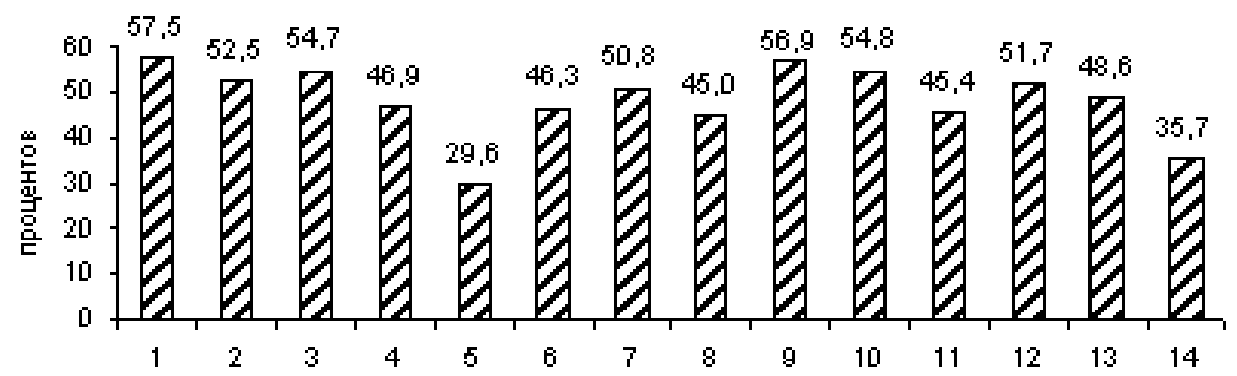

1 - Электроэнергетика

2 - Топливная промышленность

3 - Нефтедобывающая промышленность

4 - Нефтеперерабатывающая 11 Лесная, деревообрабатывающая промышленность

5 - Газовая промышленность

6 - Угольная промышленность

7 - Черная металлургия
8 - Цветная металлургия

9 - Химическая и нефтехимическая промышленность

10 Машиностроение

- и металлообработка

- и целлюлозно-бумажная промышленность

12 Промышленность строительных

- материалов

13 Легкая промышленность

14 Пищевая промышленность

* По крупным и средним коммерческим организациям.

Однако одним из условий выхода из кризиса является замещение капитала. Замещение капитала вызовет массовый инвестиционный спрос, что подтолкнет экономику к росту. Эконометрическое моделирование инвестиционного поведения, источник инвестиционного спроса, с чисто математической точки зрения лежит на поверхности. Рассмотрим мультипликатор Дж. М. Кейнса:

$$
\Delta Y=\alpha \Delta I,
$$

но валовые инвестиции I равны сумме чистых инвестиций и инвестиций, направляемых на замещение основного капитала, т.е. $I=I^{N}+I^{R}$. Тогда формула мультипликатора приобретает вид:

$$
\Delta Y=\alpha \Delta\left(I^{N}+I^{R}\right)>=\alpha_{1} \Delta I^{N}+\alpha_{2} \Delta I^{R} .
$$

Логично предположить, исходя из синергетических свойства экономической системы, что общий мультипликатор $\alpha$ больше или равен сумме частных мультипликаторов чистых инвестиций и инвестиций на возмещение основного капитала: $\alpha \geq \alpha_{1}+\alpha_{2}$. Выходит, что самый простой способ, не требующий поиска дополнительных денежных средств для роста экономики, - это постоянное замещение основного капитала, т.е. акцент перемещается на компонент $\alpha_{2} \Delta I^{R}$. Из формулы 23 следует, что весь рост экономики обеспечивается только процессом замещения устаревшего с инновационной точки зрения основного капитала. 
Тогда что же представляет собой механизм экономического роста? С экономических позиций замещение рождает инвестиционный спрос, а прирост основного капитала предопределен инвестиционным предложением. Если, например, в корпорации есть станок с программным обеспечением или компьютер и к нему приобретается дополнительный компьютер, то эта дополнительная единица и есть чистые инвестиции, а в корпорации произошел прирост основного капитала: стало две единицы оборудования. Но если происходит замена изначального оборудования по причине его ветхости, поломки или морального устаревания, то это уже процесс замещения (количество оборудования не меняется) и инвестиции, возмещающие расходы основного капитала. Инвестиционный спрос на капитальное оборудование даст толчок к спросу на комплектующие изделия, тот в свою очередь вызовет спрос на сопутствующие материалы и так далее. В конце концов цепочка взаимно вызывающего спроса дойдет до спроса на необходимое сырье, а тот вполне может предъявить новые требования к капитальному оборудованию - и так все пойдет по новому инвестиционному витку. Что, как мы видим, увеличивает стоимость корпорации, поскольку инвестиции - ключевой ее фактор.

Прирост выбытия основного капитала $\Delta I^{R}$ экономически означает запуск процесса технического перевооружения, обновления и замещения парка основного капитала. Это будет импульс, начало волны, вовлекающей в свой круговорот все остальные связанные с этим процессом отрасли экономики. Импульс в первую очередь даст толчок к росту машиностроительного комплекса. В конечном итоге эта волна дойдет до добывающих отраслей и вызовет там рост производства. Процесс замещения может вызвать настоящий инвестиционный бум, рост и расцвет экономики. И финансовые средства на выполнение этого инвестиционного процесса на счетах корпораций всегда есть. Финансовым источником прироста основного капитала $\Delta I^{N}$ является чистая прибыль корпораций (NI), источником же замещения основных средств $\Delta I^{R}$ - амортизационные отчисления (D).

Но как начать процесс замещения основного капитала, ведь без видимой причины корпорация на это не согласится. Будут работать на старом оборудовании, даже если оно уже давно морально устарело, до тех пор, пока его ветхость не станет очевидной. Ярким примером такой хозяйственной политики является работа электросетей «Мосэнерго»на сносившемся оборудовании, которая приводит к веерному отключению подстанций при низких температурах. В России идет процесс первоначального накопления капитала. Никто не думает о будущем: об инвестировании в основной капитал. Чтобы сад постоянно плодоносил, нужно сначала заложить его, а затем периодически обновлять деревья и кусты. И такому инвестиционному поведению есть объяснение: это как чисто психологические причины (эффект «влипания»), так и экономические. Во-первых, очень трудно определить момент начала инвестиционного процесса. Факты говорят о том, что с запаздыванием, как правило, начинается финансирование возмещения активов РАС, которые были израсходованы ранее. Оборудование морально устаревает быстрее, чем истечет срок полезного его использования и производитель успеет перенести стоимость оборудования на затраты. Оно всегда ломается невовремя - т.е. когда на счету нет достаточно средств, чтобы его восстановить. Капитальный ремонт оборудования проводится, как правило, с большим опозданием. Одна из причин этого состоит в том, что предсказать последствия научнотехнического прогресса практически просто невозможно (компьютеры или высокотехнологическое оборудование может морально устареть за 2-3 года, хотя срок полезного использования может составлять 10-20 лет). Например, в новом Налоговом кодексе РФ для вычислительной техники предусмотрены как линейная, так и нелинейная модели амортизации - в течение свыше 3-летнего до 5-летнего срока полезного использования, раньше они допускались в течение 10 лет [Налоговый кодекс, 2002]. Согласно Закону Мура (Гордон Мур - президент и один из основателей компании Intel), вычислительная техника морально устаревает в течение 18 месяцев. Во-вторых, к предполагаемому моменту начала инвестиционного процесса на замещение на счетах 
предприятий должна накопиться достаточная для этого сумма денег. То есть накопленные амортизации D должны быть всегда больше инвестиций, направляемых на возмещение основного капитала. Если предположить, что D - фонд амортизации, то необходимым условием инвестиционного процесса возмещения затрат является выполнение условия, при котором $D>\Delta I^{R}$. Этого можно добиться, только увеличив нормы амортизации в течение срока полезного использования оборудования. Основная идея состоит в увеличении скорости оборота основного капитала. Это необходимо, чтобы инфляция не съела инвестиционные накопления. Также надо учитывать, что в странах с плохими погодными условиями (а это, безусловно, относится и к России), климат воздействует на физический износ оборудования как экономически отрицательная экстерналия. Скорее всего, списание основного капитала на затраты должно идти по экспоненциальному закону $-e^{\gamma t}$, где $\gamma$ - норма амортизации. Ускоренная амортизация создаст условия для накопления средств, необходимых для своевременного замещения и восстановления основного капитала. Тогда у корпорации на счетах накопятся средства за счет сокращения налогооблагаемой базы и она станет инвестиционно привлекательной для бизнеса. Не жалко расставаться со старым оборудованием, когда на счетах заранее накоплены средства на его возмещение. Почему в домашних хозяйствах так много старой бытовой техники? Потому, что во многих семьях не ведется учет доходов и расходов, нет бюджета, не были запланированы заранее отчисления и накопления денег на инвестиции, а значит, в нужное время нет необходимой суммы денег на приобретение новой техники. Роль государства в стимулировании замещения основного капитала просто огромна. Государство должно постоянно подталкивать корпорации и домашние хозяйства на обновление имущества - вводя налоговые льготы, рекламируя новые товары, разрешая применять различные способы ускоренной амортизации (например, искусственное уменьшение срока полезного использования оборудования), создавая фирмы по утилизации старого оборудования. Все эти меры настраивают на инвестиционное поведение, постоянно нацеленное на техническое перевооружение основного капитала и всегда выгодное корпорации и, соответственно, экономике в целом.

\section{Заключение}

В соответствии с общей теорией и методологией корпоративных финансов определены факторы, оказывающие ключевое влияние на увеличение стоимости корпорации. На основе проведенного анализа моделей корпоративной стоимости разработаны сравнительно простые модели (16), (17) и количественные методы (20), (21) расчета стоимости корпорации в условиях неопределенности поведения финансовых и инвестиционных рынков. Ключевым фактором стоимости корпорации являются инвестиции. Будущие свободные денежные потоки определяются исходя из чувствительности к различным факторам бизнеса, сохранения эффективность (отдачи) инвестиций ROPPA (14) отчетного периода в будущем, что позволяет применять прикладные, количественные методы и модели в управлении стоимостью компании в условиях неопределенности финансового рынка. Количественные методы создают условия для оперативного и стратегического управления стоимостью, для перехода от интуитивных и субъективных убеждений менеджеров относительно стоимости к ее модельным расчетам с математической точностью и корректностью.

Итак, в ситуации, сложившейся в управлении стоимостью корпорации в условиях риска и неопределенности инвестиционного периода, добавление стоимости во многом определяется инвестированием и обновлением, а также эффективным использованием активов. Есть две возможности: или российские корпорации постоянно работают на изношенном и морально устаревшем оборудовании (активах), недополучая стоимость своего бизнеса, подвергаясь эффектам «влипания» (невозвратности денежного потока), или процесс постоянного замещения морально и физически устаревшего рабочего капитала WC обеспечит рост стоимости корпорации и соответственно рост российской экономики. 


\section{Список литературы}

1. Бернштейн П. Фундаментальные идеи финансового рынка: Эволюция. М.: Альпина Бизнес-Букс, 2009.

2. Блауг М. Методология науки, или Как экономисты объясняют // Вопросы экономики. 2004.

3. Брейли Р., Майерс С. Принципы корпоративных финансов. М.: ЗАО «Олимп-Бизнес», 2006.

4. Бригхэм Ю., Эрхарт М.: Финансовый менеджмент. СПб: Питер, 2007.

5. Винер Н.: Кибернетика или управление и связь в животном и машине М.: Наука, 1983.

6. Инвестиции в России. М.: Госкомстат, 2003, 2005.

7. Кейнс Дж. М. Общая теория занятости, процента и денег. М.: Гелиос АРВ, 1999.

8. Коупленд Т., Коллер Т., Муррин Дж: Стоимость компаний: оценка и управление. М.: ЗАО «Олимп - Бизнес», 2005.

9. Налоговый кодекс Российской Федерации. Части первая и вторая. М.: ООО «ТК Вебли», 2002.

10. Петти В: Трактат о налогах и сборах.Verbum sapienti - слово мудрым. Разное о деньгах. М.: Ось-89, 1997.

11. Рош Дж.: Стоимость компании: от желаемого к действительному. Минск: Гребцов Паблишер, 2008.

12. Kahneman, D., Tversky, A. (1979), Prospect Theory: an analysis of decision under risk by D. Kahneman, A. Tversky, Econometrica, 47( 2) (1979).

13. Thaler, R. (1980), Toward a positive theory of consumer choice, Journal of Economic Behavior and organization, 1 (1980).

14. Modigliani, F., Miller, M.H. (1963), Corporate Income Taxes and the cost of capital: Correction, The American Economic Review, 53(3) (1963) 433-443.

15. Modigliani, F., Miller, M.H. (1961), Divident Policy Growth, and the valuation of shares, The Journal of Business, 34(4) (1961) 411-433.

16. Modigliani, F., Miller, M.H. (1958), The cost of capital, corporate finance and the theory of Investment, The American Economic Review, 48(3) (1958) 261-297.

17. Ohlson, J. (2001), Discussion of Earnings, Book Value and Dividends in Equity Valuation, Contemporary Accounting Research, 18 (2001) 107-120. 